\title{
Cryoradiolysis of oxygenated cytochrome P450 17A1 with lyase substrates generates expected products.
}

Remigio Usai, ${ }^{1}$ Ilia G. Denisov ${ }^{2}$, Stephen G. Sligar, ${ }^{2}$ James R. Kincaid $^{1 *}$

${ }^{1}$ Department of Chemistry, Marquette University, P.O. Box 1881, Milwaukee, WI 53201-1881, United States and the ${ }^{2}$ Department of Biochemistry, University of Illinois at Urbana-Champaign, Urbana, Illinois 61801, United States.

"Correspondence: James R. Kincaid

E-mail: james.kincaid@marquette.edu

Fax: (414) 288-7066 Phone: (414) 288-3539

Department of Chemistry

Marquette University

Milwaukee, WI 53201-1881 


\title{
KEYWORDS
}

Heme proteins, Cytochrome P450 17A1, 17- $\alpha$ Hydroxyprogesterone, 17- $\alpha$ Hydroxypregnenolone, Cryoradiolysis, GC/MS

\begin{abstract}
ABBREVIATIONS
17-OH PREG, 17- $\alpha$ Hydroxypregnenolone; 17-OH PROG, 17- $\alpha$ Hydroxyprogesterone; AD, Androstenedione; CYP17A1, Cytochrome P450 17 A1; DHEA, Dehydroepiandrosterone; DCM, Dichloromethane; GC/MS, Gas chromatography/mass spectroscopy; M/Z, Mass to charge ratio; $\left[\mathrm{M}^{+}\right]$, Mass to charge ratio; ND, Nanodiscs; Irr., Irradiated; rR, Resonance Raman; RT, Retention time.
\end{abstract}




\begin{abstract}
When subjected to $\gamma$-irradiation at cryogenic temperatures the oxygenated complexes of Cytochrome P450 17A1 bound with either of the lyase substrates, 17-OH PREG or 17-OH PROG are shown here to generate the corresponding lyase products, dehydroepiandrosterone (DHEA) and androstenedione (AD) respectively. The current study uses gas chromatography-mass spectrometry (GC/MS) to document the presence of the initial substrates and products in extracts of the processed samples. A rapid and efficient method for the simultaneous determination of residual substrate and products by GC/MS is described without derivatization of the products. It is also shown that no lyase products were detected for similarly treated control samples containing no nanodisc associated CYP17 enzyme, demonstrating that the product is formed during the enzymatic reaction and not by GC/MS conditions nor the conditions produced by the cryoradiolysis process.
\end{abstract}




\section{INTRODUCTION}

Members of the cytochrome P450 monooxygenase family play vital roles in the synthesis and degradation of many physiologically important compounds and xenobiotics. ${ }^{1-2}$ CYP17A1, a steroidogenic cytochrome $\mathrm{P} 450$, found mainly in the adrenal glands and sex organs, ${ }^{1,3,4,5}$ is important in the production of androgens. This multifunctional enzyme catalyzes the hydroxylation of progesterone (PROG) or pregnenolone (PREG) to form 17-OH PREG or 17-OH PROG and then orchestrates the subsequent lyase reaction, where the $\mathrm{C} 17-\mathrm{C} 20$ bond is cleaved to produce DHEA from 17-OH PREG or AD from 17-OH PROG.

While there is consensus that the hydroxylation reaction proceeds through a Compound I intermediate, ${ }^{1,2}$ the precise mechanism associated with the remarkable lyase rection has been debated for decades, ${ }^{4,5,6}$ with arguments being made for either a Compound I-mediated reaction $^{1,2,7-10}$ or a peroxo-mediated scheme, ${ }^{1,2,11-10}$. This proposed scheme derives from recent studies, ${ }^{12,13}$ where samples of CYP17 and active site mutants, prepared with the Nanodisc system 14,15, were studied in the presence of the natural substrates, 17-OH PROG and 17-OH PREG, by rR spectroscopy coupled with the cryoradiolysis method introduced by Symons ${ }^{16,17}$ and refined by Hoffman and coworkers ${ }^{18,19}$. In the lyase cycle, an initially formed peroxo intermediate is converted to a new unstable peroxo-hemiketal intermediate, also documented by rR spectroscopic detection, which can decay upon annealing to room temperature to yield AD or DHEA. ${ }^{10,12,13}$

Though application of this effective combination of innovative approaches provided definitive spectroscopic evidence for the peroxo-hemiketal intermediate within this scheme, ${ }^{12,13}$ it is reasonable to question if these documented species arise only under the cryogenic temperatures employed to trap and structurally characterize these unstable intermediates. The present work utilizes GC/MS analysis ${ }^{20}{ }^{-22}$ to document product formation and show that, upon annealing to 
room temperature, these samples generate the expected lyase products, DHEA and AD, consistent with the proposed peroxo-mediated lyase reaction. ${ }^{12,13}$ 


\section{MATERIALS AND METHODS}

17- $\alpha$ Hydroxyprogesterone, dehydroepiandrosterone, and androstenedione were purchased from Sigma Aldrich (Milwaukee, WI, USA). The sample of 17- $\alpha$ Hydroxypregnenolone was purchased from Steraloids (Newport, RI, USA). All chemicals were used without further purification. The $9 \mathrm{~mm}$ inserts for the GC/MS autosampler were purchased from ThermoFisher Scientific (Milwaukee, WI, USA). Samples used in this study were samples prepared in previously reported studies ${ }^{12,13}$

\section{Instrumentation}

Chromatographic analysis was performed using a Shimadzu GC/MS system (GC2010Plus), coupled with a Shimadzu autosampler (AOC-20i + s), and GC/MS-QP2010 SE Single Quadrupole GC-MS. The software for acquisition and processing is GC/MS Solution which contains GC/MS analysis editor, GC/MS real time analysis and GC/MS Postrun analysis. The carrier gas used was Helium. A $1 \mu \mathrm{L}$ sample was injected in the split-type injector [split ratio 1:5] for all 17-OH PROG and AD standards, while a $3 \mu \mathrm{L}$ sample was used for the 17-OH PREG and DHEA standards. A $5 \mu \mathrm{L}$ sample was used for the extracted CYP17A1 samples that were prepared with either 17-OH PROG or 17-OH PREG. The standard samples were contained in $1 \mathrm{~mL}$ vials and GC/MS spectra acquired while extracted samples were contained in $200 \mu \mathrm{L}$ glass vial insert which was inserted into a $1 \mathrm{~mL}$ glass vial. The separation and resolution of metabolites was achieved using a SH-Rxi-5Sil MS (Fused silica) (30 m length x $0.25 \mathrm{~mm}$ column diameter x 0.25 $\mu \mathrm{m}$ film thickness) column (Restek, USA) which is a general-purpose low-polarity phase, Crossbond 1,4-bis(dimethylsiloxy)phenylene dimethyl polysiloxane with a temperature range of 60 to $350{ }^{\circ} \mathrm{C}$. It is engineered to be a low-bleed GC-MS column, with excellent inertness for active compounds and only $5 \%$ polarity. 


\section{GC/MS Analysis}

A blank $1 \mu \mathrm{L}$ sample of DCM was injected before running any set of samples to ensure there was no contaminating substances in the column by ensuring there were no spurious peaks in the blank run. Injection was performed in a split mode (split ratio $\mathbf{1}: \mathbf{5}$ at $250{ }^{\circ} \mathrm{C}$ ) using an autosampler, Shimadzu [SPL1]. A temperature gradient was used, the oven being programmed to start at $150{ }^{\circ} \mathrm{C}$ for $0.7 \mathrm{~min}$, ramped at $30{ }^{\circ} \mathrm{C} / \mathrm{min}$ to $280{ }^{\circ} \mathrm{C}$ and held for $15 \mathrm{~min} \cdot{ }^{20,21,23}$ This program has been shown to be useful in identification of a sample of underivatized steroids. ${ }^{23}$ The carrier gas was helium with a constant flow rate of $1.69 \mathrm{~mL} \mathrm{~min}^{-1}$. The GC/MS interface (transfer line between gas chromatograph and mass spectrometer) and ion trap temperature were set at 250 and $200{ }^{\circ} \mathrm{C}$, respectively. Mass spectra were obtained in full scan mode from m/z 90 to 500 mass range for qualitative analysis, using electron impact ionization mode, with the ionization voltage set at $70 \mathrm{eV}$.

\section{Preparation of samples}

The standard samples (commercial OH-PROG, OH-PREG) were dissolved in dichloromethane (DCM) to a final concentration of $450 \mu \mathrm{M}$ while standards for products (commercial AD and DHEA ) were dissolved to make final concentrations of $150 \mu \mathrm{M}$. GC/MS spectra of the pure standard solutions were acquired. Standard mixtures were also prepared; i.e., a mixture of $450 \mu \mathrm{M}$ 17-OH PROG with $150 \mu \mathrm{M}$ AD and a mixture of $450 \mu \mathrm{M}$ 17-OH-PREG with $150 \mu \mathrm{M}$ DHEA. The solutions were prepared by dissolving in DCM in a $1 \mathrm{~mL}$ glass vial. The mass spectra of all the compounds were consistent with mass spectra of the compounds in literature. ${ }^{23,24}$ The preparation of the cryoradiolyzed samples of CYP17A1 was described previously ${ }^{12,13}$; i.e., one sample contained $320 \mu \mathrm{M}$ ND/CYP17A1 in $100 \mathrm{mM}$ potassium phosphate (pH 7.4), $250 \mu \mathrm{M}$ sodium Chloride, $30 \%$ (vol/vol) distilled glycerol, $6.24 \mu \mathrm{M}$ methyl 
viologen, and $400 \mu \mathrm{M}$ 17-OH PROG, while the other sample contained $280 \mu \mathrm{M}$ ND/CYP17A1 in $100 \mathrm{mM}$ potassium phosphate ( $\mathrm{pH} 7.4$ ), $250 \mu \mathrm{M}$ sodium chloride, $6.24 \mu \mathrm{M}$ methyl viologen, and $400 \mu \mathrm{M}$ 17-OH PREG; this solution was mixed with distilled glycerol, 30\%(V/V). Two “control” samples, with no CYP17A1 present, were prepared for irradiation; each contained 0.30 $\mathrm{mL}$ of glycerol (Roche $99.5 \%$ pure, molecular biology grade), $0.70 \mathrm{~mL}$ of phosphate buffer $(0.30$ $\mathrm{M} \mathrm{KPi}+0.10 \mathrm{M} \mathrm{NaCl}, \mathrm{pH} 7.4)$ and $50 \mu \mathrm{L}$ of an $8 \mathrm{mM}$ solution of 17-OHPREG in methanol. One of these samples was saturated with oxygen gas ( 5 min bubbling with stirring); another sample was deaerated (5 min bubbling with argon gas with stirring). Both samples were quickly frozen by immersion into liquid nitrogen and then subjected to typical cryoradiolysis conditions; i.e., 3.5 Mrads dose of $\gamma$-rays (in the ${ }^{60}$ Cobalt irradiation chamber at the University of Illinois at Urbana Champaign).

\section{Sample extraction}

Methods of extraction and quantitation of the metabolites is a modification of methods that have been previously described elsewhere ${ }^{9,20,21,25-28}$ Briefly, an NMR tube containing frozen sample previously used for $\mathrm{rR}$ and cryoradiolysis was thawed and the $(\sim 0.1 \mathrm{~mL})$ sample was pipetted into a $2 \mathrm{~mL}$ funnel. A $1 \mathrm{~mL}$ aliquot of dichloromethane was added and the flask shaken gently for about 2-5 minutes. The flask was left standing for about 3 minutes to allow separation of the organic (DCM) and aqueous layers. The bottom organic layer containing residual substrate and product was drained into a clean, new $5 \mathrm{~mL}$ glass vial. The extraction was repeated three more times and the pooled organic layer was evaporated to dryness by flowing nitrogen gas gently over the solution. The sample was dissolved in $150 \mu \mathrm{L}$ of DCM and was transferred to a $200 \mu \mathrm{L}$ glass vial insert which was inserted into a GC/MS glass vial, placed in the Auto-sampler and GC/MS spectra acquired. 


\section{RESULTS AND DISCUSSION}

The GC/MS spectra obtained for a mixture of $450 \mu \mathrm{M} 17-\mathrm{OH}$ PROG and $150 \mu \mathrm{M}$ Androstenedione (AD) in dichloromethane (DCM) solvent is shown in Figure 1. The gas chromatogram (top) gave a retention time of $7.1 \mathrm{~min}$ for $\mathrm{AD}$ and $9.7 \mathrm{~min}$ for $17-\mathrm{OH}$ PROG. The mass spectrum (Figure 1 middle) shows the 17-OH PROG peak exhibits a parent ion peak $\left[\mathrm{M}^{+}\right]$, with an $\mathrm{m} / \mathrm{z}$ of $330 \mathrm{~g} / \mathrm{mol}$, and a fragmentation pattern that matches that reported in the literature. ${ }^{29}$ The mass spectrum of $\mathrm{AD}$ (bottom) shows the molecular ion peak $\left[\mathrm{M}^{+}\right]$of $286 \mathrm{~g} / \mathrm{mol}$, and a fragmentation pattern that matches the literature ${ }^{24}$ mass spectrum. The symmetry of the GC peak is attributed to lack of hydroxyl groups, which can lead to peak tailing.

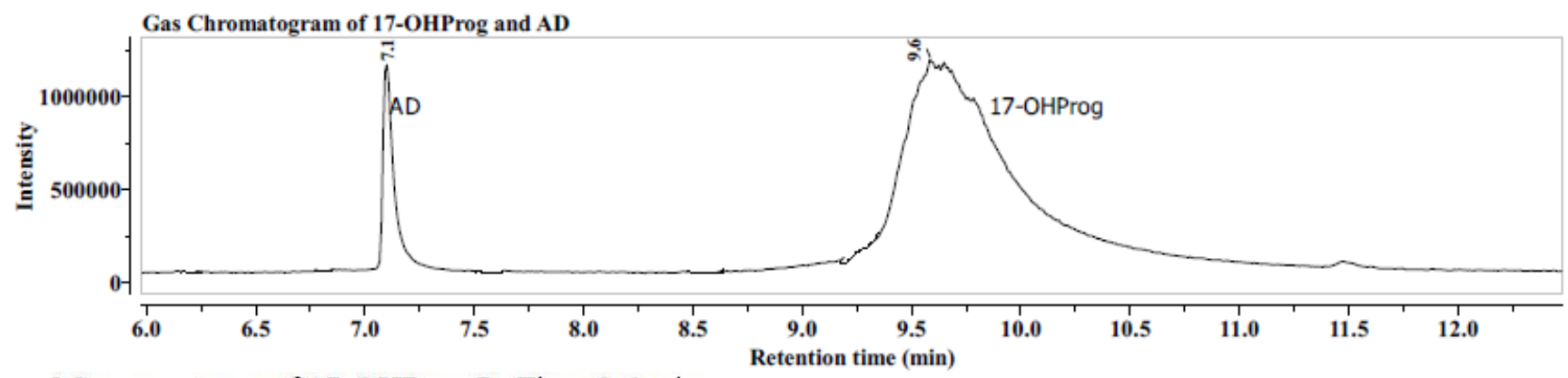

Mass spectrum of 17-OHProg R. Time $9.6 \mathrm{~min}$
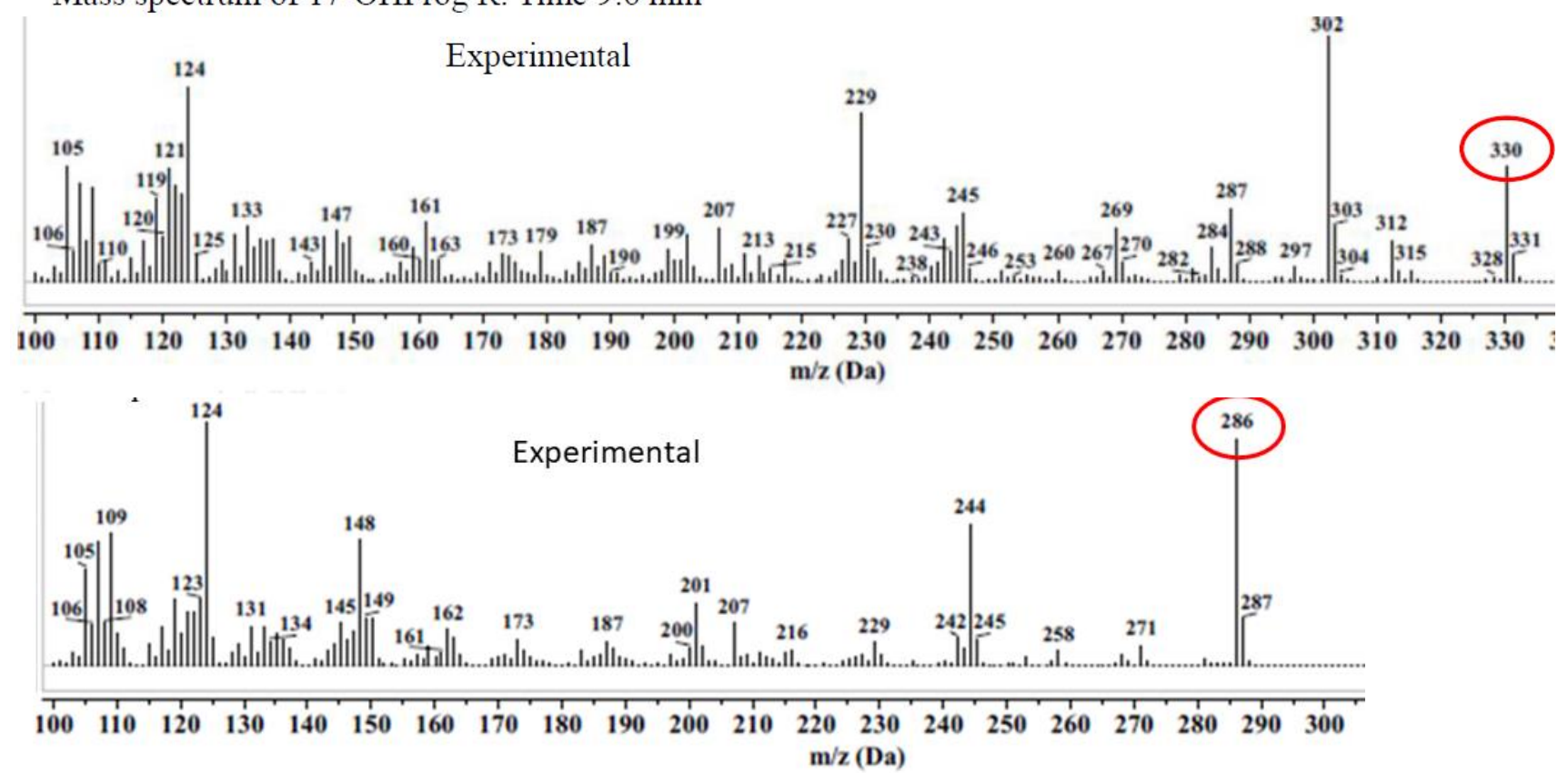
Figure 1. GC/MS of mixture of $450 \mu \mathrm{M}$ 17-OH PROG (RT 9.6) and $150 \mu \mathrm{M}$ AD (RT $7.1 \mathrm{~min}$ ) and corresponding literature spectra.

Figure 2 shows GC/MS data obtained for a sample of $320 \mu \mathrm{M}$ oxygenated Nd:CYP17A1 plus 400 $\mu \mathrm{M}$ 17-OH PROG, which was extracted from a sample that had been subjected to cryoradiolysis and annealing, followed by rR spectroscopic studies. ${ }^{12}$ The gas chromatogram (top) shows a peak corresponding to $17-\mathrm{OH}$ PROG with retention time 9.7 min, matching that observed for the standard of 17-OH PROG. This sample component exhibits a mass spectrum (middle) matching the literature spectrum as well as the mass spectrum of the standard; $\left[\mathrm{M}^{+}\right]=330$. AD was also observed with a retention time of 7.2 minutes as in standards. SpectraBase reported that a $\mathrm{m} / \mathrm{z}$ value of 286 is a signature fragmentation of androstenedione compound (Androstenedione - MS Spectrum - SpectraBase). Its full mass spectrum also matched the standards and literature data; i.e., $\left[\mathrm{M}^{+}\right]=286$. Note that some or all of the peaks including $281,191,207,, 147,133,117$ were observed especially in samples that had undergone cryoradiolysis and extraction. These peaks are caused by the background noise as concentration of samples got lower. These background peaks are due to septum and column bleeding and become more pronounced as concentration of samples decreases. As concentration of sample increase the background peaks become suppressed. We know these are background peaks as they appear at any point along the spectrum or on blank DCM or solvent blank spectrum. 

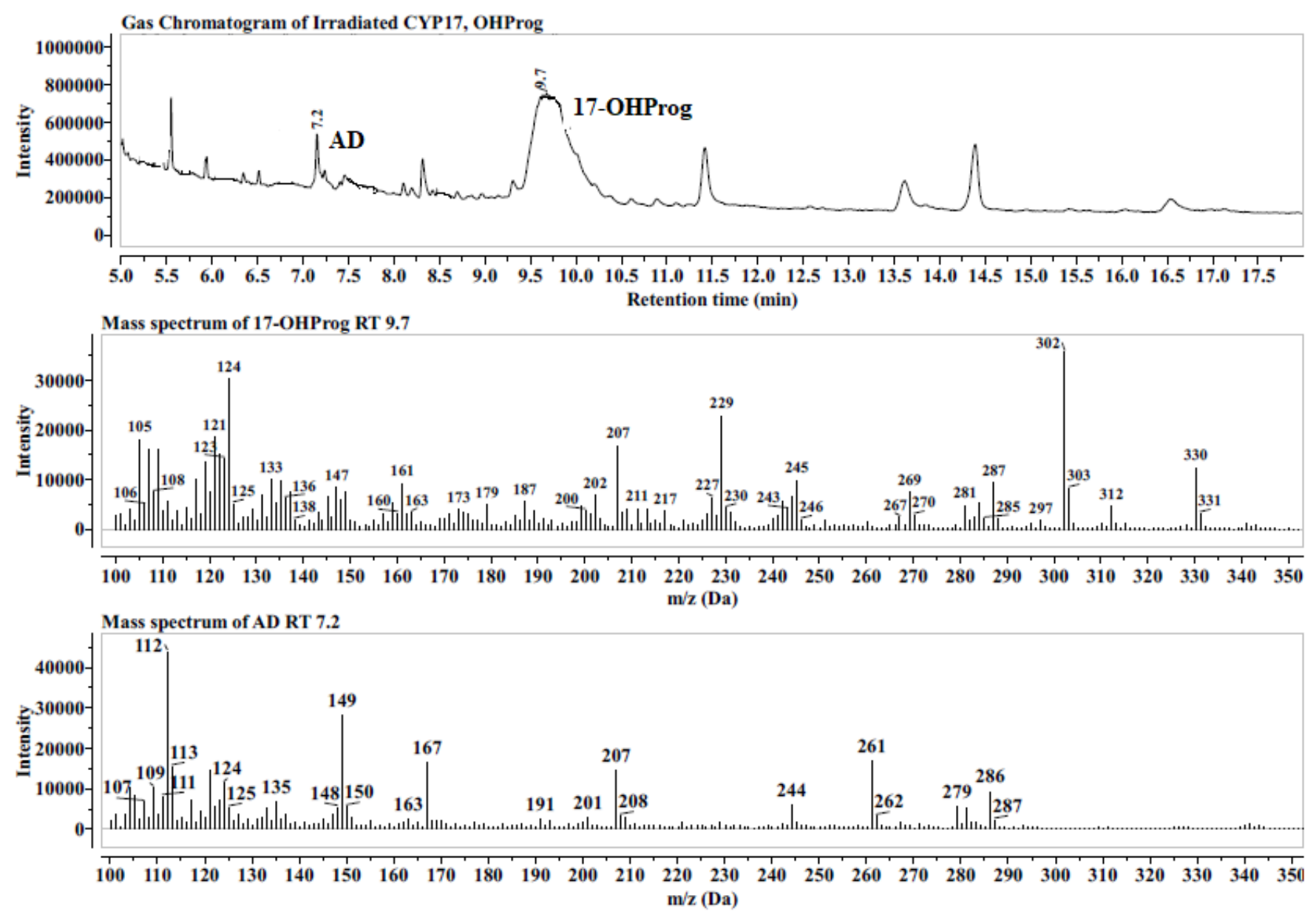

Figure 2. GC/MS of CYP17 bound to 17-OH PROG sample extracted after cryoradiolysis showing clearly the 17-OH PROG peak with retention time $9.7 \mathrm{~min}$ and AD retention time $7.2 \mathrm{~min}$ and the corresponding mass spectra with molecular ion peaks 330 and 286 respectively.

Figure 3 shows GC/MS data acquired for a sample of underivatized mixture of 17-OH PREG and DHEA in DCM. The gas chromatogram (top) exhibits some broadening and peak tailing for both peaks, a consequence of the 3-OH substituent. The retention time of OH-PREG was 10.4 min and the mass spectrum (middle) revealed the presence of a parent ion $\mathrm{m} / \mathrm{z} 332\left[\mathrm{M}^{+}\right]$with a variety of fragmentation products matching literature data. ${ }^{30}$ The peak assigned to DHEA had a retention time 7.4 min and a mass spectrum that matches the literature mass spectrum ${ }^{24}$, exhibiting a parent ion peak $\left[\mathrm{M}^{+}\right]$of 288 and appropriate fragmentation peaks. 


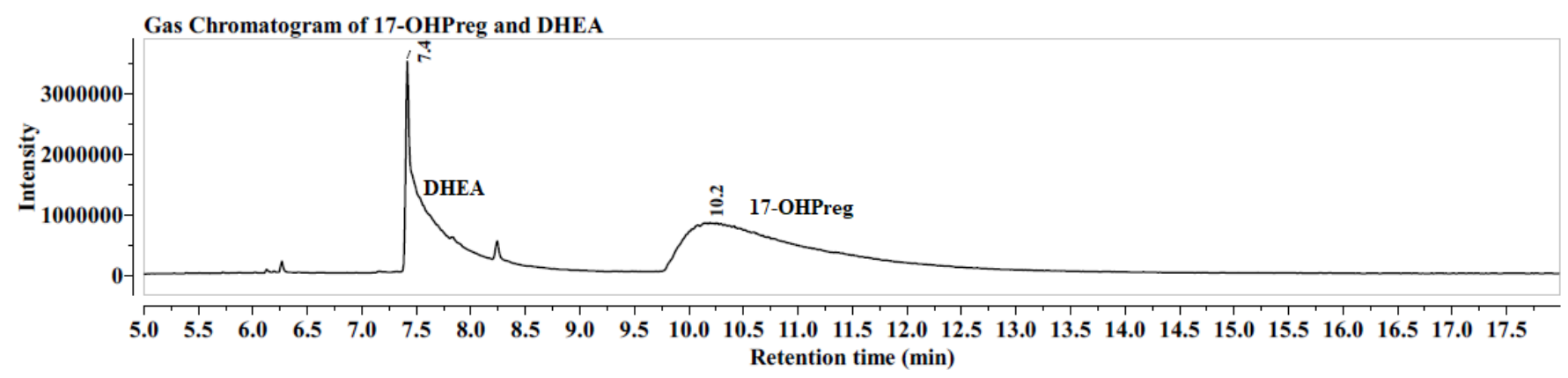

Mass spectrum of 17-OHPreg R. Time $10.2 \mathrm{~min}$

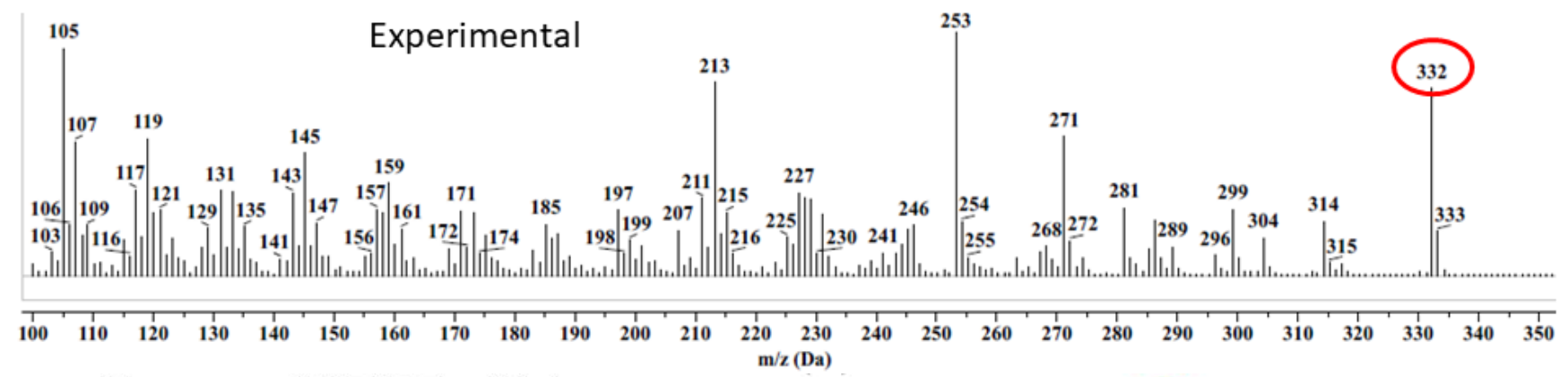
Mass spectrum of DHEA R. Time $7.4 \mathrm{~min}$

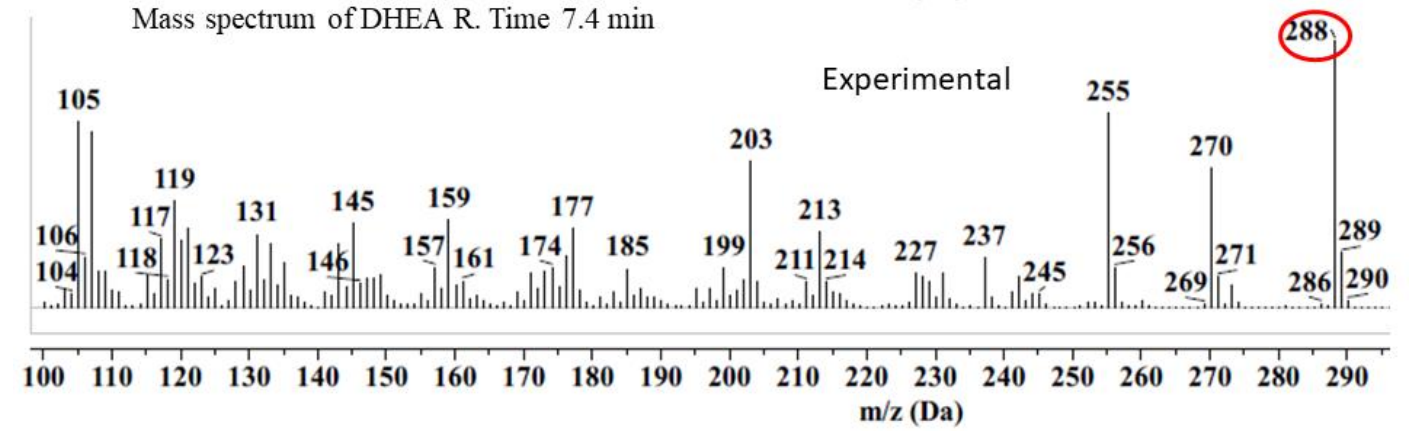

Figure 3. GC/MS of 17-OH PREG $450 \mu \mathrm{M}$ (RT 10.2 min) and DHEA $150 \mu \mathrm{M}$ (RT 7.4 min) and corresponding literature spectra

Figure 4 shows GC/MS data obtained for a sample of $280 \mu \mathrm{M}$ oxygenated Nd:CYP17A1 plus 450 $\mu \mathrm{M}$ 17-OH PREG, which was extracted from an NMR tube that had been subjected to cryoradiolysis and rR spectroscopic studies, ${ }^{31}$ followed by later annealing to room temperature. The gas chromatogram (top) shows a peak corresponding to 17-OH PREG with retention time 10.3, matching that observed for the standard of 17-OH PREG, and exhibits a mass spectrum (middle) matching the literature spectrum and the mass spectrum of standards; $\left[\mathrm{M}^{+}\right]=332$. DHEA 
was also observed with a retention time of 7.5 as in standards. SpectraBase reported that a $\mathrm{m} / \mathrm{z}$ value of 288 is a signature fragmentation of dehydroepiandrosterone compound (dehydroepiandrosterone - MS - Spectrum - SpectraBase) Its mass spectrum matched the standards and literature data with $\left[\mathrm{M}^{+}\right]=288$.
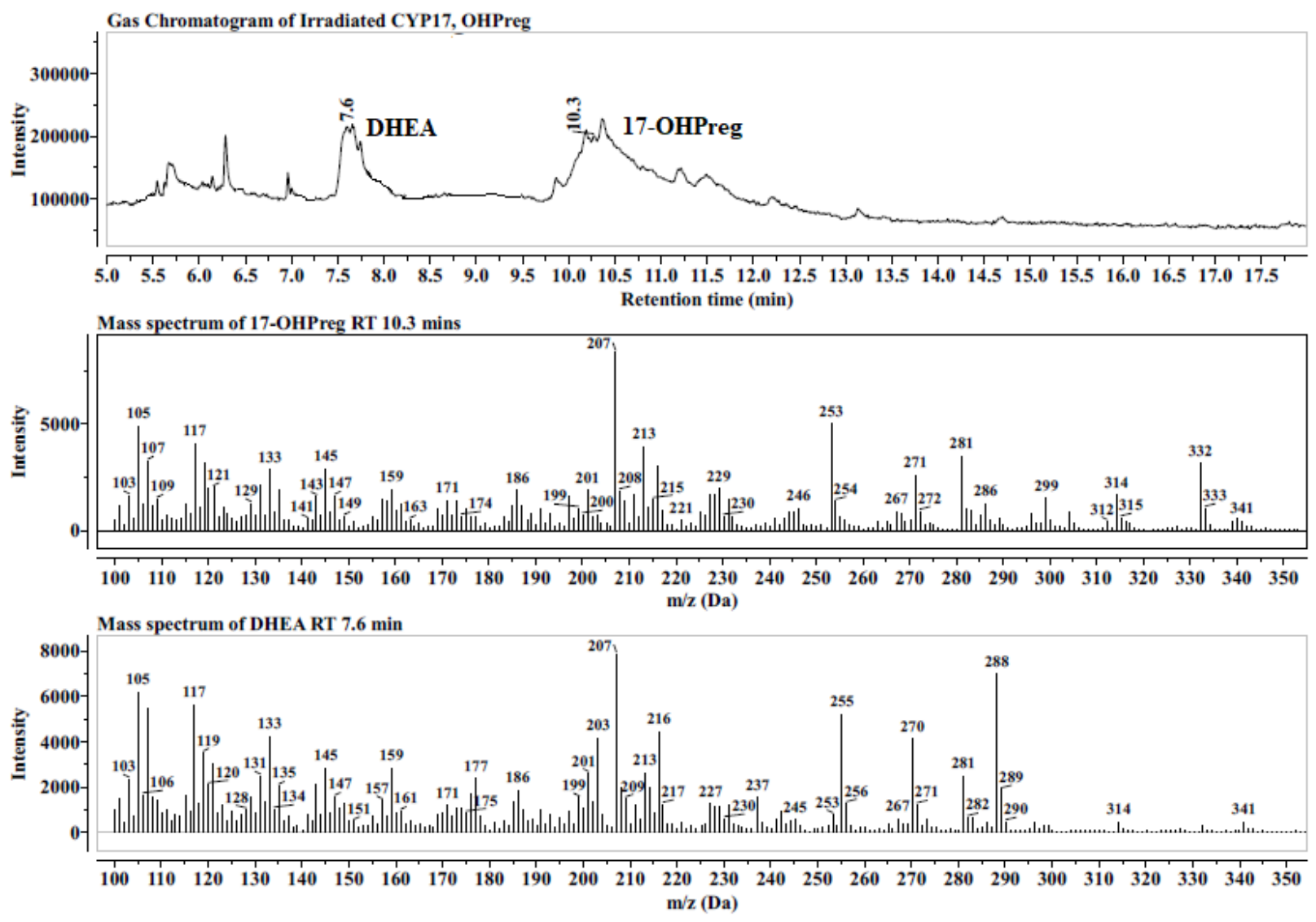

Figure 4. GC/MS spectrum of CYP17 bound to 17-OH PREG after irradiation and cryoradiolysis. 
Table 1. Retention times and molecular masses from GC/MS spectra of steroids studied using the temperature program and conditions outlined above.

\begin{tabular}{cccc}
\hline Steroid & $\begin{array}{c}\text { Molecular ion } \\
\text { peak }\left[\mathrm{M}^{+}\right]\end{array}$ & \multicolumn{2}{c}{ Retention Time/ Minutes } \\
\hline 17-OH Prog & 330 & Standard Mixture & $\begin{array}{c}\text { Extracted } \\
\text { CYP17A1 sample }\end{array}$ \\
\hline 17-OH Preg & 332 & 10.6 & 9.7 \\
\hline AD & 286 & 7.1 & 10.3 \\
\hline AD & 288 & 7.4 & 7.2 \\
\hline
\end{tabular}




\section{CONCLUSIONS}

Previous studies have shown analysis of steroids by GC/MS with or without derivatization. This is a report to detail analysis of steroids from cryoradiolysis and annealing using GC/MS. The experimental results show that we can successfully characterize steroid metabolites from Cytochrome P450 17A1 after cryoradiolysis and annealing including 17-OH PROG and 17-OH PREG, AD and DHEA by GC/MS without derivatization. From the results, we observed peaks with corresponding retention times as in pure standards e.g. 17-OH PREG shows a parent ion $\left[\mathrm{M}^{+}\right] \mathrm{m} / \mathrm{z}$ of $332 \mathrm{~g} / \mathrm{mol}$ and a retention time of about $10.4 \mathrm{~min}$ in both the standards and CYP17 sample extracted. The same was observed for the interesting peak of DHEA product with the parent ion peak $\left[\mathrm{M}^{+}\right]$of $288 \mathrm{~g} / \mathrm{mol}$ and retention time around $7.5 \mathrm{~min}$ in both standards (Figure 3) and sample (Figure 4). No DHEA was observed in the control, showing that no DHEA was formed in the GC/MS column or during irradiation procedure. For the CYP17 sample, other peaks could be from other products including lipids and any other products formed. It has been established that cryoradiolysis products matches those obtained from studies in fluid solution.

\section{ACKNOWLEDGEMENTS}

This work was supported by a grant from the National Institutes of Health GM125303 (JRK) and GM118145 (SGS). We greatly appreciate the help of Dr. Jay A. LaVerne while using the ${ }^{60} \mathrm{Co}$ source at the Notre Dame Radiation Laboratory (Notre Dame University, IN), which is a facility of the U.S. Department of Energy, Office of Basic Energy Sciences. We also greatly appreciate the help of Dr. Cai Sheng for his guidance and assistance in using the new GC/MS instrument. 


\section{REFERENCES}

(1) Cytochrome P450: Structure, Mechanism, and Biochemistry, 4th ed. (Ed.: Ortiz de Montellano, P. R.), Springer, Heidelberg, 2015.

(2) Hrycay, E. G.; Bandiera, S. M. Monooxygenase, Peroxidase and Peroxygenase Properties and Reaction Mechanisms of Cytochrome P450 Enzymes. Adv. Exp. Med. Biol. 2015, 851:1-61.

(3) The Ubiquitous Roles of Cytochrome P450 Proteins. Metal Ions in Life Sciences, Vol 3; A. Sigel, H. Sigel, R. K. S., Ed.; John Wiley \& Sons, Ltd, 2007.

(4) Auchus, R. J.; Lee, T. C.; Miller, W. L. Cytochrome B5 Augments the 17,20-Lyase Activity of Human P450c17 without Direct Electron Transfer. J. Biol. Chem. 1998, 273 (6), 3158-3165.

(5) Gonzalez, E.; Johnson, K. M.; Pallan, P. S.; Phan, T. T. N.; Zhang, W.; Lei, L.; Wawrzak, Z.; Yoshimoto, F. K.; Egli, M.; Peter Guengerich, F. Inherent Steroid 17a,20-Lyase Activity in Defunct Cytochrome P450 17A Enzymes. J. Biol. Chem. 2018, 293 (2), 541556.

(6) Bonomo, S.; Jørgensen, F. S.; Olsen, L. Mechanism of Cytochrome P450 17A1-Catalyzed Hydroxylase and Lyase Reactions. J. Chem. Inf. Model. 2017, 57 (5), 1123-1133.

(7) Rittle, J.; Green, M. T. Cytochrome P450 Compound I: Capture, Characterization, and CH Bond Activation Kinetics. Science. 2010, 330 (6006), 933-937.

(8) Krest, C. M.; Onderko, E. L.; Yosca, T. H.; Calixto, J. C.; Karp, R. F.; Livada, J.; Rittle, J.; Green, M. T. Reactive Intermediates in Cytochrome P450 Catalysis. J. Biol. Chem. 2013, 288 (24), 17074-17081.

(9) Khatri, Y.; Gregory, M. C.; Grinkova, Y. V.; Denisov, I. G.; Sligar, S. G. Active Site Proton Delivery and the Lyase Activity of Human CYP17A1. Biochem. Biophys. Res. Commun. 2014, 443 (1), 179-184.

(10) Gregory M., Mak P. J., Sligar S. G., Kincaid J. R., Differential Hydrogen Bonding in Human CYP17 Dictates Hydroxylation versus Lyase Chemistry., Angew. Chem. Int. Ed. 2013, 52 (20), 5342-5345.

(11) Gilep, A. A.; Sushko, T. A.; Usanov, S. A. At the Crossroads of Steroid Hormone Biosynthesis: The Role, Substrate Specificity and Evolutionary Development of CYP17. Biochim. Biophys. Acta - Proteins Proteomics 2011, 1814 (1), 200-209.

(12) Mak, P. J.; Gregory, M. C.; Denisov, I. G.; Sligar, S. G.; Kincaid, J. R. Unveiling the Crucial Intermediates in Androgen Production. Proc. Natl. Acad. Sci. U. S. A. 2015, 112 (52), 15856-15861.

(13) Mak, P. J.; Duggal, R.; Denisov, I. G.; Gregory, M. C.; Sligar, S. G.; Kincaid, J. R. Human Cytochrome CYP17A1: The Structural Basis for Compromised Lyase Activity with 17-Hydroxyprogesterone. J. Am. Chem. Soc. 2018, 140 (23), 7324-7331.

(14) Nath, A.; Atkins, W. M.; Sligar, S. G. Current Topics Applications of Phospholipid 
Bilayer Nanodiscs in the Study of Membranes and Membrane Proteins. Biochemistry 2007, 46 (8), 2059-2069.

(15) Sligar, S. G. Finding a Single-Molecule Solution for Membrane Proteins. Biochem. Biophys. Res. Commun. 2003, 312 (1), 115-119.

(16) Symons, M. C. R.; Peterson, R. L. Electron Capture by Oxyhaemoglobin: An Esr Study. Proc. R. Soc. London, Ser. B. 1978, 201, 285-300.

(17) Kappl, R.; Höhn-Berlage, M.; Hüttermann, J.; Bartlett, N.; Symons, M. C. R. Electron Spin and Electro Nuclear Double Resonance of the [FeO2]- Centre from Irradiated Oxyhemo- and Oxymyoglobin. Biochim. Biophys. Acta (BBA)/Protein Struct. Mol. 1985, 827 (3), 327-343.

(18) Davydov, R.; Macdonald, I. D. G.; Makris, T. M.; Sugar, S. G.; Hoffman, B. M. EPR and ENDOR of Catalytic Intermediates in Cryoreduced Native and Mutant Oxy-Cytochromes P450cam: Mutation-Induced Changes in the Proton Delivery System. J. Am. Chem. Soc. 1999, 121 (45), 10654-10655.

(19) Davydov, R.; Makris, T. M.; Kofman, V.; Werst, D. E.; Sligar, S. G.; Hoffman, B. M. Hydroxylation of Camphor by Reduced Oxy-Cytochrome P450cam: Mechanistic Implications of EPR and ENDOR Studies of Catalytic Intermediates in Native and Mutant Enzymes. J. Am. Chem. Soc. 2001, 123 (7), 1403-1415.

(20) Moreira, F. de L.; De Souza, G. H. B.; Rodrigues, I. V.; Lopes, N. P.; De Oliveira, A. R. M. A Non-Michaelian Behavior of the in Vitro Metabolism of the Pentacyclic Triterpene Alfa and Beta Amyrins by Employing Rat Liver Microsomes. J. Pharm. Biomed. Anal. 2013, 84, 14-19.

(21) Oh, H. A.; Lee, H.; Kim, D.; Jung, B. H. Development of GC-MS Based Cytochrome P450 Assay for the Investigation of Multi-Herb Interaction. Anal. Biochem. 2017, 519, 71-83.

(22) Kitson, F. G.; Larsen, B. S.; McEwen, C. N. Gas Chromatography and Mass Spectrometry- A Practical Guide; Carlifonia, 1996.

(23) Mak, P. J.; Gregory, M. C.; Sligar, S. G.; Kincaid, J. R. Resonance Raman Spectroscopy Reveals That Substrate Structure Selectively Impacts the Heme-Bound Diatomic Ligands of CYP17. Biochemistry 2014, 53 (1), 90-100.

(24) Matsuyama S., W. N. Intergrated Spectral Database System of Organic Compounds. Natl. Inst. Adv. Ind. Sci. Technol.

(25) Gregory, M. C.; Denisov, I. G.; Grinkova, Y. V.; Khatri, Y.; Sligar, S. G. Kinetic Solvent Isotope Effect in Human P450 CYP17A1-Mediated Androgen Formation: Evidence for a Reactive Peroxoanion Intermediate. J. Am. Chem. Soc. 2013, 135 (44), 16245-16247.

(26) Duggal, R.; Liu, Y.; Gregory, M. C.; Denisov, I. G.; Kincaid, J. R.; Sligar, S. G. Evidence that Cytochrome $\mathrm{B}_{5}$ acts as a redox donor in CYP17A1 mediated androgen synthesis. Biochem. Biophys. Res. Commun. 2016, 477 (2), 202-208.

(27) Koo, L. S.; Immoos, C. E.; Cohen, M. S.; Farmer, P. J.; Ortiz de Montellano, P. R. 
Enhanced Electron Transfer and Lauric Acid Hydroxylation by Site-Directed Mutagenesis of CYP119. J. Am. Chem. Soc. 2002, 124 (20), 5684-5691.

(28) Morlock, L. K.; Grobe, S.; Balke, K.; Mauersberger, S.; Böttcher, D.; Bornscheuer, U. T. Protein Engineering of the Progesterone Hydroxylating P450-Monooxygenase CYP17A1 Alters Its Regioselectivity. ChemBioChem 2018, 19 (18), 1954-1958.

(29) McDonald, J. G.; Matthew, S.; Auchus, R. J. Steroid Profiling by Gas ChromatographyMass Spectrometry and High Performance Liquid Chromatography-Mass Spectrometry for Adrenal Diseases. Horm. Cancer 2011, 2 (6), 324-332.

(30) Mak, P. J.; Gregory, M. C.; Sligar, S. G.; Kincaid, J. R. Resonance Raman Spectroscopy Reveals That Substrate Structure Selectively Impacts the Heme-Bound Diatomic Ligands of CYP17. Supporting Information. Biochemistry 2014, 53 (3), 13.

(31) Mak, P. J.; Piotr J. Mak. Resonance Raman Spectroscopy as a Structural Probe of the Cytochrome P450 Enzymatic Cycle. In Handbook of the Porphyrin Science; Kadish, K. M.; Smith, K.; Guilard, R., Ed.; 2016; Vol. 42, pp 1-120. 